\title{
Effect of miR-145 on gastric cancer cells
}

\author{
JIA WANG $^{1}$, ZHENG SUN $^{2}$, SHIHAI YAN ${ }^{3}$ and FENG GAO ${ }^{1}$ \\ ${ }^{1}$ Laboratory Department; ${ }^{2}$ Digestive Oncology Department; ${ }^{3}$ Pharmacology Laboratory, \\ Affiliated Hospital of Nanjing University of TCM, Nanjing, Jiangsu 210000, P.R. China
}

Received December 29, 2017; Accepted October 3, 2018

DOI: $10.3892 / \mathrm{mmr} .2019 .10015$

\begin{abstract}
Gastric cancer is one of the most common malignant tumors in the world. Due to the lack of early diagnosis and effective treatment, the outcome of treatment and prognosis is poor. MicroRNA-145 (miR-145) is downregulated in various cancer types. In the present study, miR-145 expression was detected by reverse transcription-quantitative polymerase chain reaction in gastric cancer cell lines and normal gastric epithelial cells. The function of miR-145 in the gastric cancer cell line SGC-7901 was investigated. The present results demonstrated that the expression of miR-145 was downregulated in gastric cancer cells. Further analysis identified that upregulation of miR-145 significantly suppressed SGC-7901 cell proliferation, increased cellular apoptosis and blocked the cell cycle in the $\mathrm{G}_{1}$ phase. Additionally, overexpression of miR-145 reduced SGC-7901 cell invasion and metastasis in vitro. Western blot analysis demonstrated that overexpression of miR-145 downregulated Myc proto-oncogene protein, phosphoinositide 3-kinase/protein kinase B and matrix metalloproteinase 2/9, and upregulated p21 in SGC-7901 cells. The present results revealed potential signaling pathways that miR-145 may use to regulate gastric cancer cell proliferation, apoptosis and metastasis. Collectively, the present results suggest that miR-145 is a tumor suppressor for gastric cancer and it may be a potential therapeutic target for gastric cancer treatment.
\end{abstract}

\section{Introduction}

Gastric cancer is one of the most common malignancies in the world with poor prognosis $(1,2)$. Despite the reduced incidence in recent decades, gastric cancer remains the third leading cause of global cancer-associated mortality, and has the highest incidence in East Asia $(3,4)$. The early diagnosis of gastric cancer requires improvement, as it frequently only identified in the advanced stage (5). Therefore, the prognosis

Correspondence to: Dr Feng Gao, Laboratory Department, Affiliated Hospital of Nanjing University of TCM, 155 Hanzhong Road, Nanjing, Jiangsu 210000, P.R. China

E-mail: gaofeng295968@163.com

Key words: microRNA-145, gastric cancer, apoptosis, cell cycle, invasion, migration of patients with gastric cancer is very poor (6-8). The primary reason for failure in the treatment of gastric cancer is cell infiltration and metastasis (9).

MicroRNAs (miRNAs/miRs) are evolutionarily conserved non-coding RNA of $\sim 19-25$ nucleotides, which function by regulating one or more mRNA to regulate gene expression for translation inhibition or cleavage $(10,11)$. miR serve a key role in cell proliferation, cell death and organ development $(12,13)$. In addition, previous studies demonstrated that miRs are key regulators in the development and progression of gastric cancer $(14,15)$. However, the expression status and biological function of specific miRs in gastric cancer require further examination. miR-145 was first reported to be consistently decreased in precancerous colorectal lesions (16). Other previous studies observed that miR-145 as a tumor-suppressive miRNA regulates cell growth in tumor cells by targeting epidermal growth factor receptor, Myc proto-oncogene protein (c-Myc) and POU domain, class 5, transcription factor 1 (17-20). In addition, miR-145 has been studied in gastric cancer (21). Lei et al (22) reported that miR-145 inhibits gastric cancer cell migration and metastasis by inhibiting MYO6 expression. The results of the research of Qiu et al (23) indicated that miR-145 suppressed the proliferation, migration, invasion and cell cycle progression of gastric cancer cells through decreasing Sp1 expression. Gao et al (24) suggested that miR-145 suppresses gastric cancer metastasis by inhibiting $\mathrm{N}$-cadherin protein translation. However, the exact function and underlying molecular mechanism of miR-145 in gastric cancer remains largely unclear and requires further examination.

In the present study, the expression of miR-145 was significantly decreased in gastric cancer cells. Further, miR-145 overexpression was able to inhibit the proliferation of gastric cancer cells and induce apoptosis. In addition, it was observed that miR-145 mimics inhibited gastric cancer cell invasion and migration by regulating the phosphoinositide 3-kinase $(\mathrm{PI} 3 \mathrm{~K}) /$ protein kinase $\mathrm{B}(\mathrm{AKT})$ signaling pathway. The present results demonstrated that miR-145 functions as an anti-tumor gene in gastric cancer cell, and is a potential therapeutic target.

\section{Materials and methods}

Cell culture and transfection. Gastric cancer cell line SGC-7901 and normal gastric epithelial cells GES-1 were obtained from the Cell Bank of Chinese Academy of Sciences (Shanghai, China). All cells were cultured in RPMI-1640 medium supplemented with $10 \%$ fetal bovine serum (FBS; 
both Gibco; Thermo Fisher Scientific, Inc., Waltham, MA, USA) and $1 \%$ penicillin/streptomycin. Cells were incubated in a humidified incubator at $37^{\circ} \mathrm{C}$ and $5 \% \mathrm{CO}_{2}$.

The miR-145 mimics (5'-GTCCAGTTTTCCCAGGAA TCCCT-3') $(50 \mathrm{nM})$, miR-145 inhibitor (5'-AGGGATTCC TCCCAAAACTGGAC-3') $(100 \mathrm{nM})$ and the negative control vector (5'-GUAGGAGUAGUGAAAGGCC-3') (NC; $50 \mathrm{nM}$; Shanghai GenePharma Co., Ltd., Shanghai, China) were transfected into SGC-7901 cells using Lipofectamine ${ }^{\circledR} 2000$ (Invitrogen; Thermo Fisher Scientific, Inc.) according to the manufacturer's protocol. After transfection for 48-72 h, cells were collected for further assays. Cells in the blank group (BL) were untreated cells.

Cell proliferation. The proliferation of SGC-7901 cells transfected with miR-145 mimics, miR-145 inhibitor or NC were examined using MTT colorimetric assays. After transfection for $48 \mathrm{~h}$, SGC-7901 cells $\left(1 \times 10^{5}\right)$ were seeded in 96-well plates in triplicate. MTT $(20 \mu 1 ; 5 \mathrm{mg} / \mathrm{ml}$; Sigma-Aldrich; Merck KGaA, Darmstadt, Germany) was added to each well at $48 \mathrm{~h}$ after transfection. Following incubation for $4 \mathrm{~h}$, the MTT medium was removed and $150 \mu 1$ dimethyl sulfoxide was added. After shaking for $15 \mathrm{~min}$ at room temperature, the optical density at the $490 \mathrm{~nm}$ of each sample was determined with scanning multi-well spectrophotometer.

Flow cytometry analysis. SGC-7901 cells were transfected with miR-145 mimics, miR-145 inhibitor or NC, and $48 \mathrm{~h}$ after transfection, the cells were collected and washed with PBS. To detect the cell cycle, the cells were fixed in $70 \%$ methanol at $-20^{\circ} \mathrm{C}$ overnight. Subsequently, the cells were washed with PBS twice and stained with propidium iodide (PI). Finally, flow cytometry was used to detect cell cycle.

To detect cellular apoptosis, cells were stained with an Annexin V/PI (apoptosis detection kit; BD Biosciences, Franklin Lakes, NJ, USA) according to the manufacturer's protocol. After incubating with Annexin V/PI for $15 \mathrm{~min}$ in the dark, cellular apoptosis (Q1: Dead cells; Q2: Late apoptosis; Q3: Normal cells; Q4: Early apoptosis) was detected using a flow cytometer (BD Biosciences, Franklin Lakes, NJ, USA). Data were analyzed by using WinMDI version 2.5 (Purdue University Cytometry Laboratories; http://www.cyto.purdue. edu/flowcyt/software/Catalog.htm).

Cell invasion assay. The effect of miR-145 on SGC-7901 cell invasive capability was detected using a 24-well Transwell plate ( $8 \mathrm{~mm}$ pore size; Corning Incorporated, Corning, NY, USA). Chamber inserts were coated with $200 \mathrm{mg} / \mathrm{ml}$ Matrigel and dried overnight under sterile conditions. SGC-7901 cells were transfected with miR-145 mimic, miR-145 inhibitor or NC, and $48 \mathrm{~h}$ after transfection, the cells $\left(1 \times 10^{4}\right)$ in RPMI-1640 medium were added to the top chamber, and RPMI-1640 medium supplemented with $20 \%$ FBS was added to the lower chamber. Following incubation for $48 \mathrm{~h}$ at $37^{\circ} \mathrm{C}$, the top chambers were wiped with cotton wool to remove the noninvasive cells and subsequently fixed in $100 \%$ methanol at room temperature for $10 \mathrm{~min}$. Following staining in hematoxylin-eosin solution at room temperature for $20 \mathrm{~min}$, the invading cells on the underside of the membrane were counted at five random fields under a light microscope (Olympus Corporation, Tokyo, Japan).
Cell migration assay. The scratch wound healing assay was used to detect the effect of miR-145 on SGC-7901 cell metastasis. SGC-7901 cells were transfected with miR-145 mimics, miR-145 inhibitor or NC, and cells $\left(1 \times 10^{4}\right.$ cells/well) were subsequently seeded homogeneously on 6-well plates. When the cells formed a monolayer, a sterile plastic $200 \mu$ l pipette tip was used to scratch the cells. The floating cells were washed with RPMI-1640 medium. At 0, 24 and $48 \mathrm{~h}$ after scratch wound formation, images were obtained using an inverted microscope at a magnification of $\times 200$ and measured using Image-Pro Plus software version 7.0 (Media Cybernetics, Inc., Rockville, MD, USA).

Western blot analysis. SGC-7901 cells, which were transfected with miR-145 mimics, miR-145 inhibitor or NC for $48 \mathrm{~h}$, were collected and the total proteins were extracted using $40 \mathrm{mM}$ Tris- $\mathrm{HCl}(\mathrm{pH}$ 7.4) containing $150 \mathrm{mM} \mathrm{NaCl}$ and $1 \%$ (v/v) Triton X-100, supplemented with protease inhibitors. Protein concentration was determined using the bicinchoninic acid protein assay. Equal amounts of protein $(30 \mu \mathrm{g}$ per lane) were resolved on $10 \%$ SDS-PAGE, and subsequently transferred to a polyvinylidene difluoride membrane (EMD Millipore, Billerica, MA, USA). Following blocking with 5\% skimmed milk in Tris buffered saline with $0.1 \%$ Tween-20 at room temperature for $1.5 \mathrm{~h}$, samples were probed with antibodies against c-Myc (1:1,000; cat. no. 5605; Cell Signaling Technology, Inc., Danvers, MA, USA), phosphorylated (p-)AKT (1:1,000; cat. no. 4060; Cell Signaling Technology, Inc.), PI3K (1:1,000; cat. no. 4249; Cell Signaling Technology, Inc.), P21 (1:1,000; cat. no. 2947; Cell Signaling Technology, Inc.), matrix metalloproteinase (MMP) 2 (1:1,000; cat. no. 40994; Cell Signaling Technology, Inc.), MMP9 (1:1,000; cat. no. 13667; Cell Signaling Technology, Inc.) and GAPDH (1:1,000; cat. no. 8884; Cell Signaling Technology, Inc.). Following washing with 1X PBST (10 min/wash) for three times, blots were incubated with horseradish peroxidase-conjugated secondary antibody (1:2,000; cat. no. 7074; Cell Signaling Technology, Inc.) at room temperature for $2 \mathrm{~h}$. Immunoreactive bands were visualized using SignalFire ${ }^{\mathrm{TM}}$ Plus ECL Reagent (cat no. 12630; Cell Signaling Technology, Inc.). The protein expression levels of the stripes were normalized based on the gray value of GAPDH. Image J version 2.0 software (Bio-Rad Laboratories Inc, USA) was used to quantify the intensity of the bands.

Reverse transcription-quantitative polymerase chain reaction (RT-qPCR). Total RNA was extracted from cells using RNAiso Plus (Takara Biotechnology Co., Ltd., Dalian, China) according to the manufacturer's protocol. RT was conducted to synthesize cDNA with the ThermoScript RT-PCR system (Invitrogen; Thermo Fisher Scientific, Inc.) according to the manufacturer's protocol. qPCR was performed to analyze the synthesized cDNA by using the SYBR ${ }^{\circledR}$ Premix Ex Taq ${ }^{\mathrm{TM}}$ II kit (Takara Bio, Inc., Otsu, Japan). Primer sequences were listed as following: U6 forward: 5'GCTTCGGCAGCACAT ATACTAAAAT3' and reverse: 5'CGCTTCACGAATTTG CGTGTCAT3'; miR-145 forward: 5'-GTCCAGTTTTCCCAG GAATCCCT-3' and reverse: 5'-GCTGTCAACGATACGCTA CCTA-3'. The conditions of qPCR used for amplification were as follows: $95^{\circ} \mathrm{C}$ for $5 \mathrm{~min}, 40$ cycles at $95^{\circ} \mathrm{C}$ for $30 \mathrm{sec}, 55^{\circ} \mathrm{C}$ for $30 \mathrm{sec}, 72^{\circ} \mathrm{C}$ for $30 \mathrm{sec}$, and $72^{\circ} \mathrm{C}$ for $10 \mathrm{~min}$. U6 served as 
A

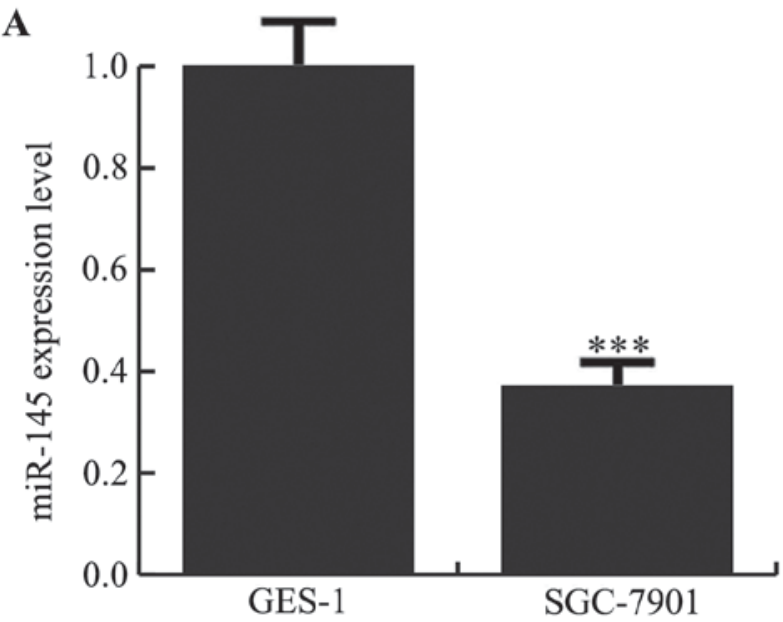

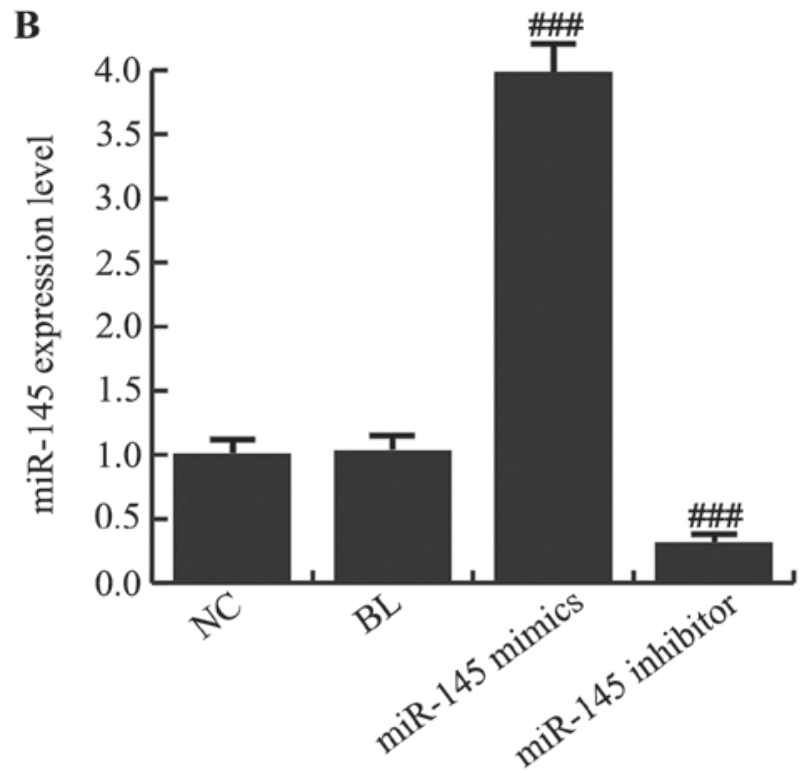

Figure 1. miR-145 is downregulated in SGC-7901 cells. (A) Relative miR-145 expression in the gastric cancer cell line SGC-7901 and normal gastric epithelial cells GES-1 was detected using reverse transcription-polymerase chain reaction. (B) Relative miR-145 expression in SGC-7901 cells in different groups. ${ }^{* * *} \mathrm{P}<0.001$ vs. GES-1; \#\# $\mathrm{P}<0.001$ vs. NC group. miR, micro RNA; NC, negative control; BL, blank.

an internal control. The relative gene expression was assessed by using the $2^{-\Delta \Delta \mathrm{Cq}}$ method (25). The experiment was repeated at least three times.

Statistical analysis. SPSS version 17.0 software (SPSS, Inc., Chicago, IL, USA) was used to analyze the data. Dare are presented as the mean \pm standard deviation of experiments performed in triplicate. Data were analyzed by one-way analysis of variance followed by Tukey's post-hoc test, or the Student's t-test. $\mathrm{P}<0.05$ was considered to indicate a statistically significant difference.

\section{Results}

miR-145 inhibits the proliferation of SGC-7901 cells. The RT-qPCR results demonstrated that the expression of miR-145 was significantly decreased in the gastric cancer cell line SGC-7901 compared with normal gastric epithelial GES-1 cells (Fig. 1A; $\mathrm{P}<0.001$ ). To expand the limited understanding of the role served by miR-145 in gastric cancer cells, the effects of miR-145 gain and loss-of-function on SGC-7901 cells were examined. For this, miR-145 mimics, miR-145 inhibitor or NC were transfected into SGC-7901 cells, and RT-qPCR was performed to detect the transfection efficiency. As presented in Fig. 1B, miR-145 mimics significantly increased the expression level of miR-145 in SGC-7901 cells and the expression level of miR-145 was significantly decreased in the miR-145 inhibitor-transfected SGC-7901 cells $(\mathrm{P}<0.001)$. After transfection for $48 \mathrm{~h}$, cell morphology was imaged (Fig. 2A), and cells were plated into 96 -well plates to measure the absorbance. The MTT results demonstrated that transfection with miR-145 mimics significantly suppressed SGC-7901 cell proliferation compared with the NC (Fig. 2B; $\mathrm{P}<0.001)$.

miR-145 mimics promotes SGC-7901 cell apoptosis. SGC-7901 cell apoptosis was detected $48 \mathrm{~h}$ after transfection with miR-145 mimics, miR-145 inhibitor or NC (Fig. 3A). Flow cytometry analysis revealed that early apoptosis and late apoptosis were upregulated in miR-145 mimics transfected SGC-7901 cells compared with the NC (Fig. 3B). These data demonstrated that overexpression of miR-145 induced gastric cancer cellular apoptosis.

miR-145 mimics induces cell-cycle arrest in SGC-7901 cells. Cell cycle analysis was used to examine the possible mechanism by which miR-145 inhibits proliferation. SGC-7901 cells, which were transfected with miR-145 mimics, miR-145 inhibitor or NC for $48 \mathrm{~h}$, were detected by cell cycle analysis (Fig. 4A). The results suggested that overexpression of miR-145 significantly increased the percentage of cells in the $G_{1}$ phase (Fig. 4B; $\mathrm{P}<0.001$ ).

Overexpression of miR-145 inhibits the invasion and migration of gastric cancer cells. To investigate the metastatic effect of miR-145 on SGC-7901 cells, migration and invasion assays were performed. The mimics of miR-145 and NC were transfected into SGC-7901 cells, which were identified to express relatively low levels of miR-145. The results of the Matrigel Transwell assay demonstrated that numbers of adhesive cells in the miR-145 mimics group was significantly decreased compared with the NC group (Fig. 5A and B; $\mathrm{P}<0.05)$. To examine whether cell migration ability was similarly suppressed by miR-145 overexpression, a scratch wound healing assay was performed. The results revealed that overexpression of miR-145 suppressed the wound healing rate of SGC-7901 cells compared with the NC group (Fig. 5C and D). Collectively, these data suggested that miR-145, as a regulatory molecule, is involved in gastric cancer cell migration and invasion.

miR-145 inhibits SGC-7901 cell growth by regulating the PI3K/AKT signaling pathway. To further investigate the 
A

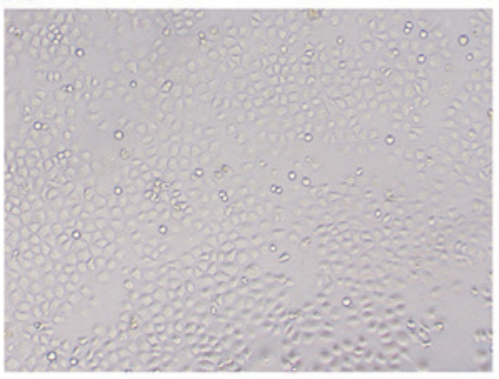

miR-145 mimics

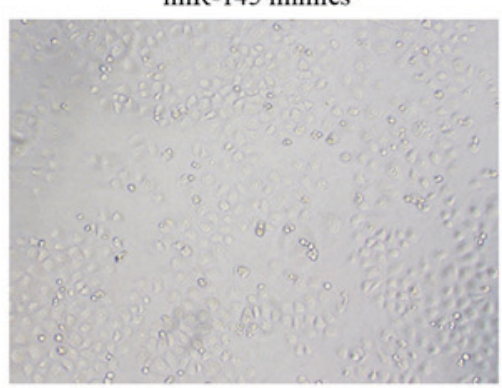

BL

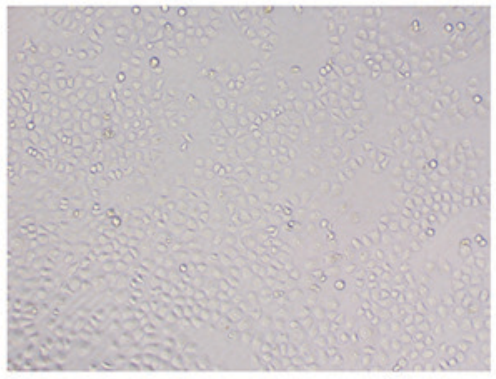

miR-145 inhibitor

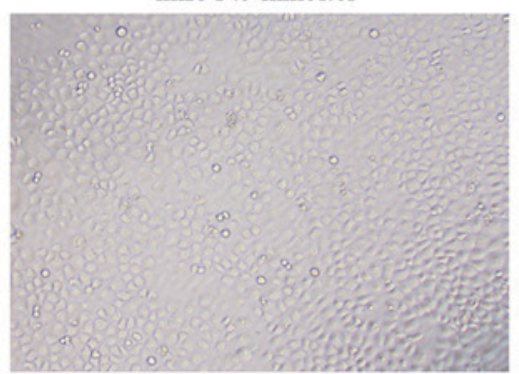

B

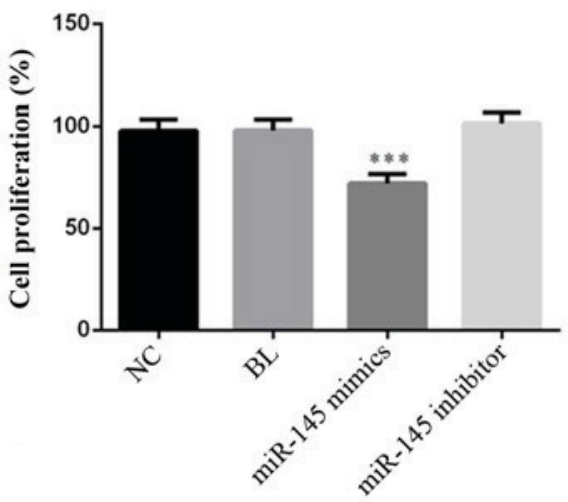

Figure 2. miR-145 mimics inhibits the proliferation of SGC-7901 cells. (A) Cell morphology was imaged with a microscope (magnification, x200). (B) Cell proliferation was detected by an MTT assay. ${ }^{* * *} \mathrm{P}<0.001$ vs. NC group. miR, micro RNA; NC, negative control; BL, blank.

A
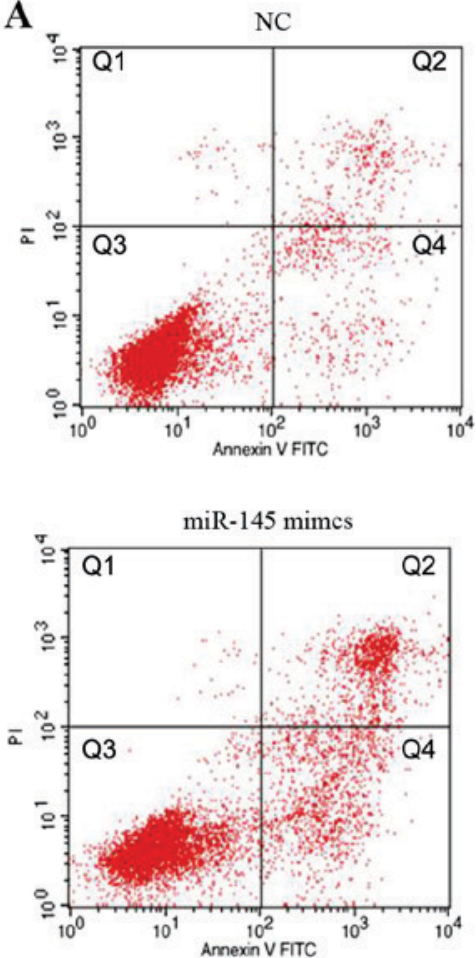
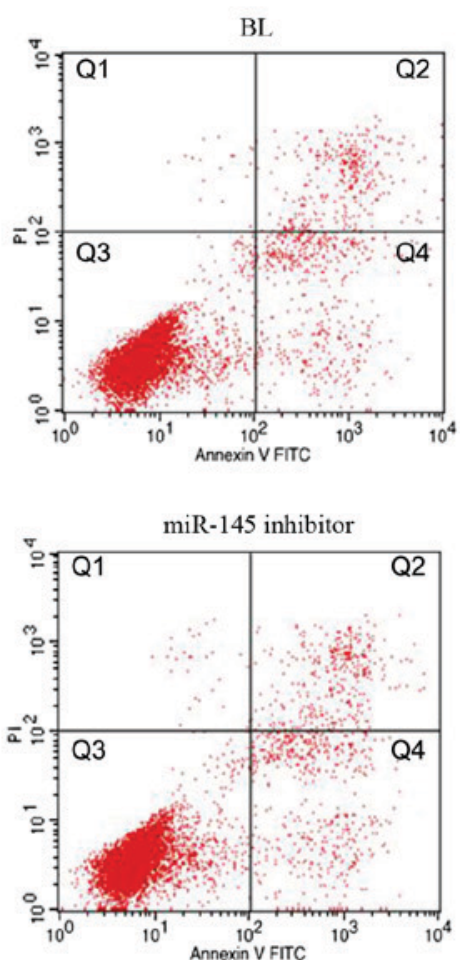

B

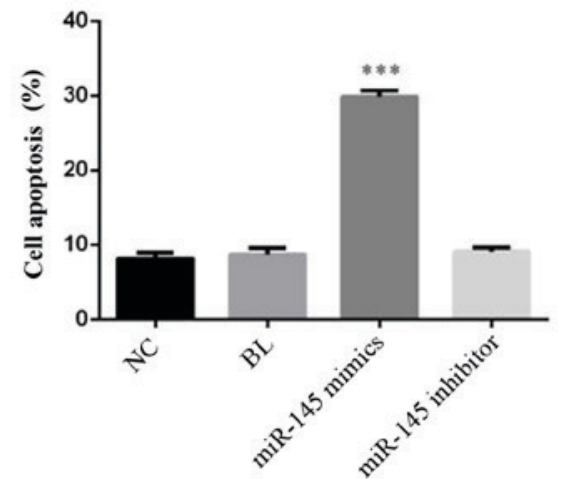

Figure 3. Effects of overexpression miR-145 on cellular apoptosis of gastric cancer cells. (A) Cellular apoptosis (Q1: Dead cells; Q2: Late apoptosis; Q3: Normal cells; Q4: Early apoptosis) was detected by flow cytometry and (B) the rate of apoptosis was analyzed. ${ }^{* * *} \mathrm{P}<0.001$ vs. NC group. miR, micro RNA; NC, negative control; BL, blank; PI, propidium iodide; FITC, fluorescein isothiocyanate.

molecular mechanisms regulated by miR-145, western blotting was performed to detect c-Myc, PI3K, p-AKT, MMP2 and MMP9 in SGC-7901 cells transfected with the miR-145 mimics, miR-145 inhibitor or NC. The data demonstrated that overexpression of miR-145 decreased protein expression levels of c-Myc, PI3K, p-AKT, MMP2 and MMP9 (Fig. 6).
Western blot analysis demonstrated that the expression of $\mathrm{p} 21$, a cell cycle regulatory protein, was significantly increased, suggesting that miR-145 may block the cell cycle by regulating p21 expression. These data revealed the potential molecular mechanism of miR-145 inhibiting gastric cancer progression involves these proteins. 

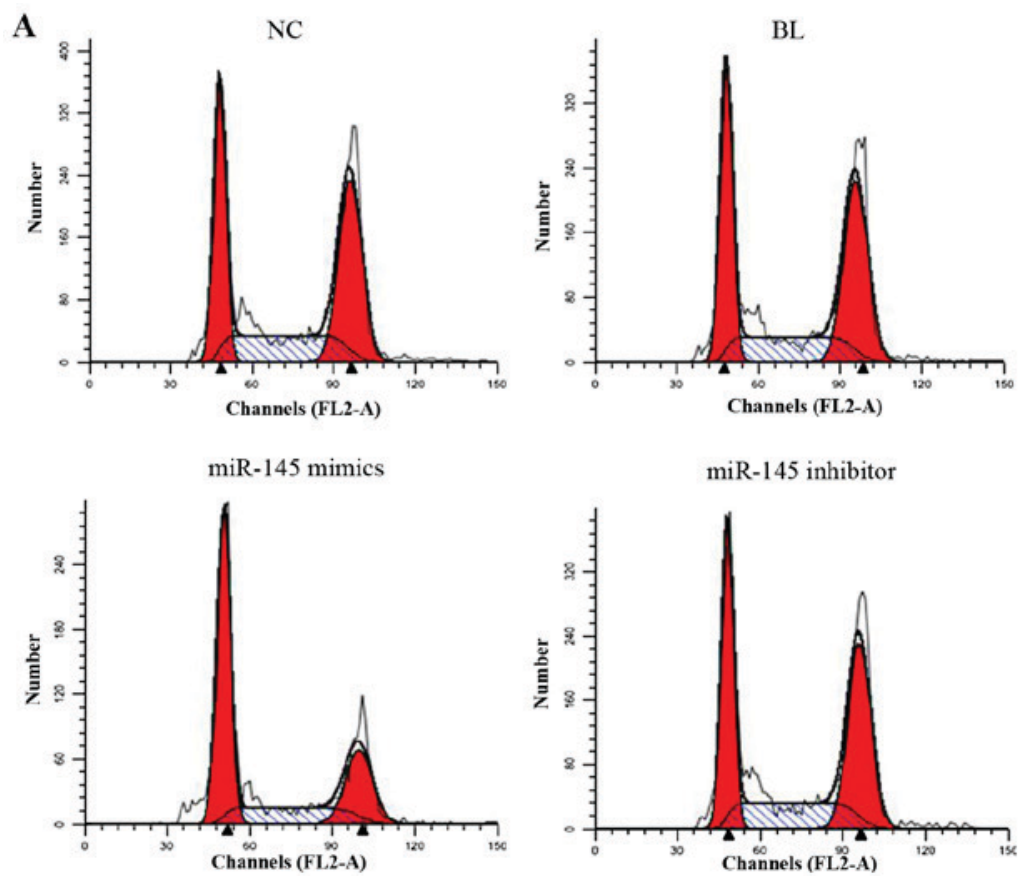

B

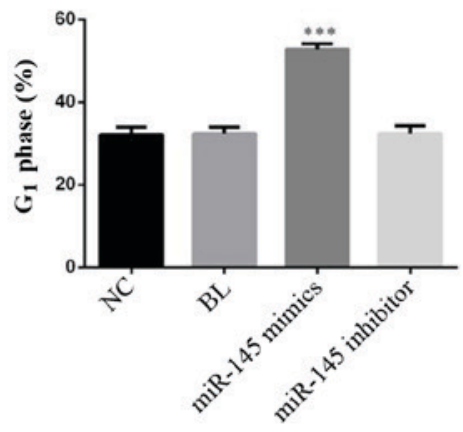

Figure 4. miR-145 mimics induces cell-cycle arrest in SGC-7901 cells. (A) Cell cycle was detected by flow cytometry and (B) the percentage of $\mathrm{G}_{1}$ phase was analyzed. ${ }^{* * *} \mathrm{P}<0.001$ vs. NC group. miRNA, micro RNA; NC, negative control; BL, blank.

A

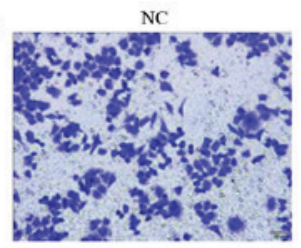

miR-145 mimics

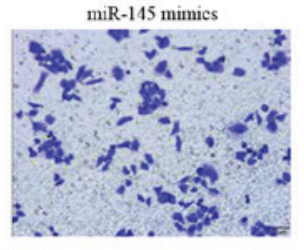

C
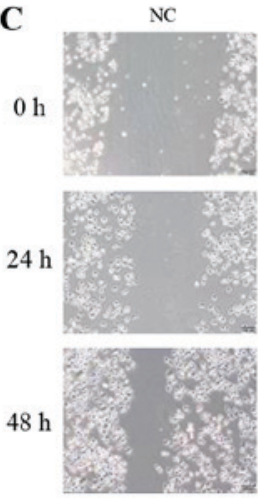

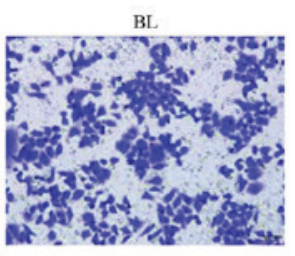

miR-145 inhibitor

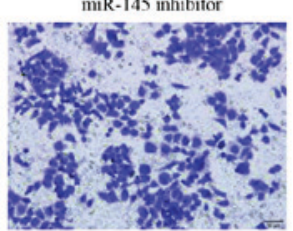

BL
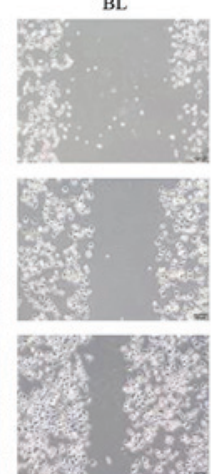

miR-145 mimics
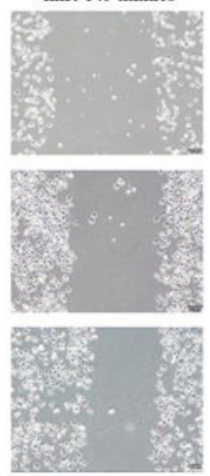

B

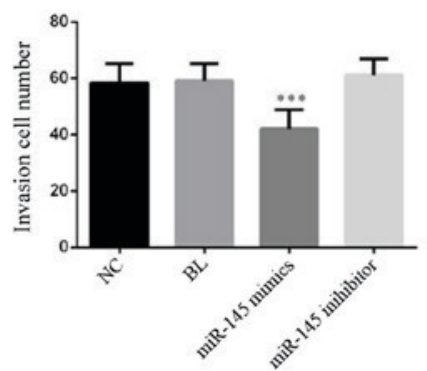

miR-145 inhibitor

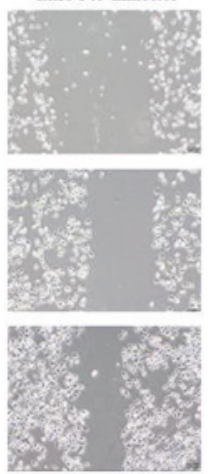

D

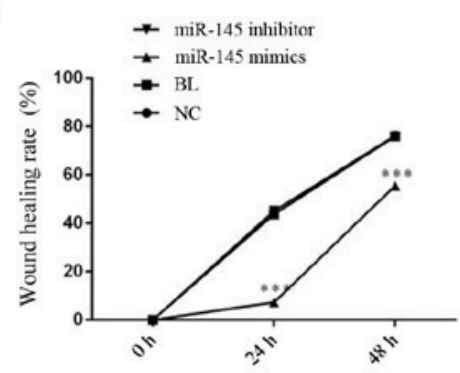

Figure 5. Effect of miR-145 on SGC-7901 cell invasion and migration. (A) Transwell assay was used to detect cell invasion and (B) invasive cell number was determined. (C) Scratch wound healing assays were performed to detect cell migration at 0, 24 and $48 \mathrm{~h}$ after scratch wound formation, images were obtained (magnification, $\mathrm{x} 200$ ) and (D) analyzed. ${ }^{* * *} \mathrm{P}<0.001$ vs. NC group. miRNA, micro RNA; NC, negative control; BL, blank.

\section{Discussion}

In previous years, research has revealed the occurrence and development of gastric cancer. Gastric cancer remains one of the most common malignancies and causes approximately one million novel cases each year in the world (26). miRNA has been reported to express abnormalities or mutations in various tumors. Previous studies demonstrated that miR-145 is 

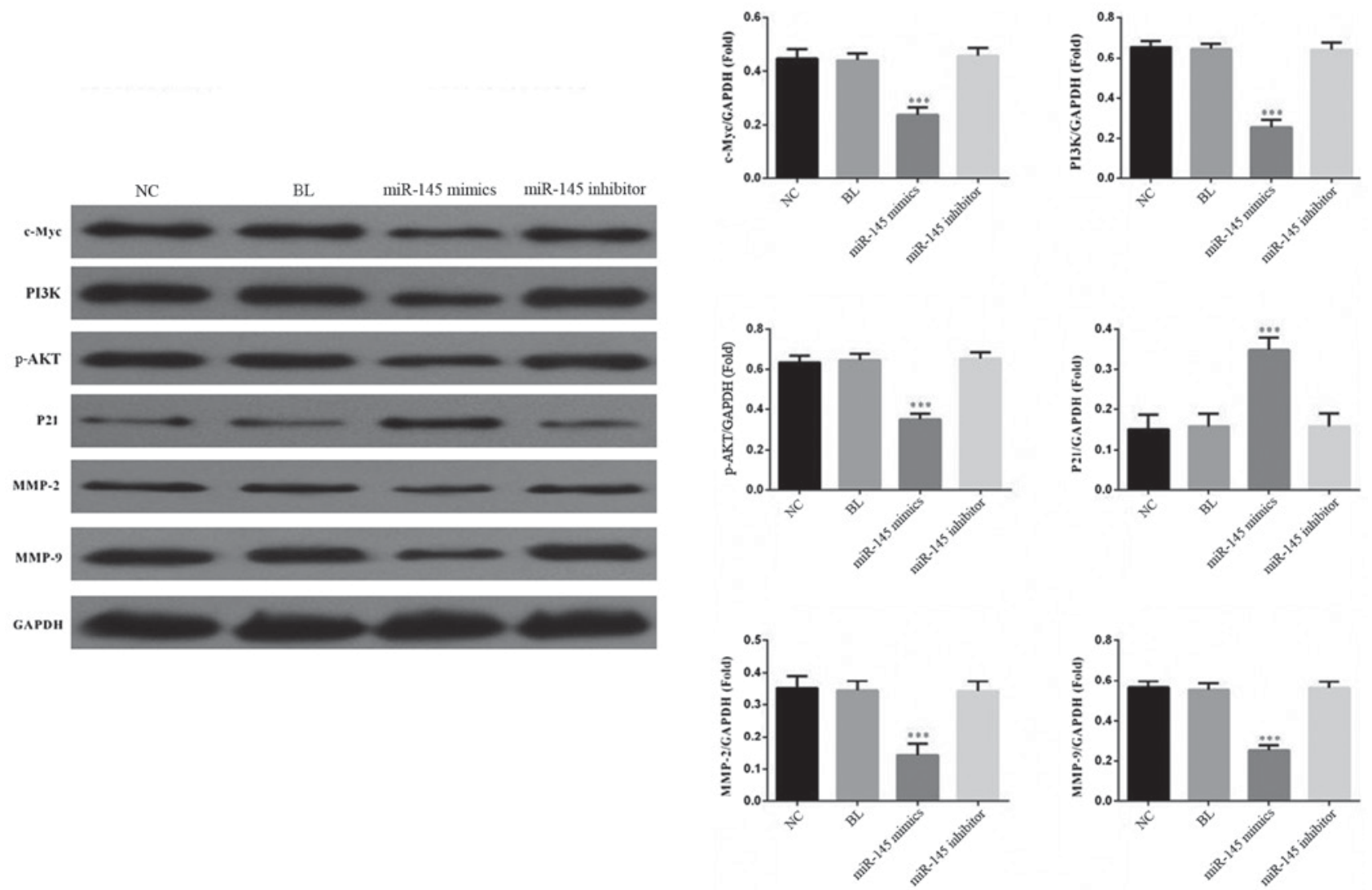

Figure 6. miR-145 inhibits SGC-7901 cell growth by regulating the PI3K/AKT signaling pathway. miR-145 overexpression significantly decreased the expression of PI3K, p-AKT, c-Myc, MMP2 and MMP9 while increased the expression of p21. ${ }^{* * *} \mathrm{P}<0.001 \mathrm{vs.} \mathrm{NC}$ group. miRNA, micro RNA; NC, negative control; BL, blank; PI3K, phosphoinositide 3-kinase; p-AKT, phosphorylated protein kinase B; c-Myc, Myc proto-oncogene protein; MMP, matrix metalloproteinase.

commonly downregulated in various types of cancer (27-30), thus in the present study, the role of miR-145 in gastric cancer was evaluated.

The miR-145 expression was examined in gastric cancer SGC-7901 cells and normal gastric epithelial cells GES-1. Consistent with a previous study, the present study identified that the expression of miR-145 significantly decreased in gastric cancer cells (22). Furthermore, the role of miR-145 in gastric cancer was investigated. Transfection with miR-145 mimics suppressed SGC-7901 cell growth, induced cellular apoptosis and blocked cell cycle in the $\mathrm{G}_{1}$ phase. Overexpression of miR-145 was able to inhibit SGC-7901 cell invasion and migration. Collectively, miR-145 as a tumor suppressor may inhibit gastric cancer progression. Although the present results are consistent with previous studies (22-24), there were differences. The present study systematically studied the effect of miR-145 on biological behavior, including proliferation, apoptosis, migration, invasion and cell cycle distribution of gastric cancer cells for the first time, to the best of the authors' knowledge. Different from other previous studies, the effect of miR-145 downregulation on gastric cancer cells was additionally investigated. Furthermore, notably, a novel molecular mechanism of the influence of miR-145 on the biological behavior of gastric cancer cells was identified in the present study.

c-Myc, an oncogene, is involved in cell proliferation, transformation and cell death regulation (31). Increased c-Myc protein expression levels strongly contribute to the apoptotic stimuli of epithelial cells, including DNA damage (32). Therefore, the downregulation of c-Myc is necessary for cell cycle arrest (33). In the present study, c-Myc expression was significantly decreased in miR-145 overexpressed SGC-7901 cells. In addition, overexpression of miR-145 was able to inhibit the SGC-7901 cell proliferation and block cell cycle in $\mathrm{G}_{1}$ phase, which were consistent with a previous study (34). c-Myc may be a potential target of miR-145.

The PI3K/AKT signaling pathway may regulate a variety of biological functions. Activated AKT may induce a downstream phosphorylation cascade, regulation of cell growth and survival, proliferation and apoptosis, angiogenesis, cell migration and cell cycle and other cell activity and biological effects $(35,36)$. In the present study, it was observed that overexpression of miR-145 in SGC-7901 cells decreased the protein expression level of PI3K and p-AKT. The present data suggested that miR-145 suppressed gastric cancer cell growth by regulating the PI3K/AKT signaling pathway.

The primary reason for the failure of gastric cancer treatment is cell infiltration and metastasis. The present study demonstrated that gastric cancer cell invasion and migration was suppressed by miR-145. In the MMP family, MMP2 and MMP9 are the most important enzymes to degrade type IV collagen and serve an important role in tumor vascularization, tumor cell invasion and metastasis formation (37). Therefore, the expression level of MMP2 and MMP9 were detected in the present study, and it was observed that MMP2 and MMP9 protein were decreased in miR-145 mimics transfected 
SGC-7901 cells. These data suggested that miR-145 inhibited gastric cancer cell invasion and metastasis by regulating MMP2 and MMP9 expression.

In conclusion, the present study demonstrated that miR-145 is downregulated in gastric cancer cells. Furthermore, it was identified that miR-145 inhibited SGC-7901 cell proliferation and induced cellular apoptosis through repression of the pro-oncogene c-Myc. In addition, miR-145 suppressed gastric cancer cell invasion and metastasis by regulating MMP2 and MMP9 expression. Therefore, restoration of miR-145 may be utilized as a potential novel therapeutic strategy in gastric cancer in the future.

\section{Acknowledgements}

Not applicable.

\section{Funding}

The present study was supported by the Project of National Clinical Research Base of Traditional Chinese Medicine in Jiangsu, China (grant no. JD201511).

\section{Availability of data and materials}

The analyzed data sets generated during the present study are available from the corresponding author on reasonable request.

\section{Authors' contributions}

JW and ZS assessed and analyzed the data, and contributed to the paper preparation. SY contributed to data analysis. FG collaborated to design the study. All authors collaborated to interpret the results and develop the manuscript.

\section{Ethics approval and consent to participate}

Not applicable.

\section{Patient consent for publication}

Not applicable.

\section{Competing interests}

The authors declare that they have no competing interests.

\section{References}

1. Jemal A, Bray F, Center MM, Ferlay J, Ward E and Forman D: Global cancer statistics. CA Cancer J Clin 61: 69-90, 2011.

2. Xu AM, Huang L, Liu W, Gao S, Han WX and Wei ZJ: Neoadjuvant chemotherapy followed by surgery versus surgery alone for gastric carcinoma: Systematic review and meta-analysis of randomized controlled trials. PLoS One 9: e86941, 2014.

3. Ferlay J, Shin HR, Bray F, Forman D, Mathers C and Parkin DM: Estimates of worldwide burden of cancer in 2008: GLOBOCAN, 2008. Int J Cancer 127: 2893-2917, 2010.

4. Torre LA, Bray F, Siegel RL, Ferlay J, Lortet-Tieulent J and Jemal A: Global cancer statistics, 2012. CA Cancer J Clin 65 : $87-108,2015$
5. Song Z, Wu Y, Yang J, Yang D and Fang X: Progress in the treatment of advanced gastric cancer. Tumour Biol 39: 1010428317714626, 2017.

6. Memon MA, Subramanya MS, Khan S, Hossain MB, Osland E and Memon B: Meta-analysis of D1 versus D2 gastrectomy for gastric adenocarcinoma. Ann Surg 253: 900-911, 2011.

7. Xu AM, Huang L, Zhu L and Wei ZJ: Significance of peripheral neutrophil-lymphocyte ratio among gastric cancer patients and construction of a treatment-predictive model: A study based on 1131 cases. Am J Cancer Res 4: 189-195, 2014.

8. Huang L, Xu A, Li T, Han W, Wu S and Wang Y: Detection of perioperative cancer antigen 72-4 in gastric juice pre-and post-distal gastrectomy and its significances. Med Oncol 30: 651, 2013.

9. Ghosn M, Tabchi S, Kourie HR and Tehfe M: Metastatic gastric cancer treatment: Second line and beyond. World J Gastroenterol 22: 3069-3077, 2016.

10. Hammond SM: An overview of microRNAs. Adv Drug Deliv Rev 87: 3-14, 2015

11. Wilson RC and Doudna JA: Molecular mechanisms of RNA interference. Annu Rev Biophys 42: 217-239, 2013.

12. Guo H, Ingolia NT, Weissman JS and Bartel DP: Mammalian microRNAs predominantly act to decrease target mRNA levels. Nature 466: 835-840, 2010.

13. Miska EA: How microRNAs control cell division, differentiation and death. Curr Opin Genet Dev 15: 563-568, 2010.

14. Ueda T, Volinia S, Okumura H, Shimizu M, Taccioli C, Rossi S, Alder H, Liu CG, Oue N, Yasui W, et al: Relation between microRNA expression and progression and prognosis of gastric cancer: A microRNA expression analysis. Lancet Oncol 11: 136-146, 2010.

15. Volinia S, Calin GA, Liu CG, Ambs S, Cimmino A, Petrocca F, Visone R, Iorio M, Roldo C, Ferracin M, et al: A microRNA expression signature of human solid tumors defines cancer gene targets. Proc Natl Acad Sci USA 103: 2257-2261, 2006.

16. Michael MZ, O'Connor SM, van Holst Pellekaan NG, Young GP and James RJ: Reduced accumulation of specific microRNAs in colorectal neoplasia. Mol Cancer Res 1: 882-891, 2003.

17. Hu J, Guo H, Li H, Liu Y, Liu J, Chen L, Zhang J and Zhang N: MiR-145 regulates epithelial to mesenchymal transition of breast cancer cells by targeting Oct4. PLoS One 7: e45965, 2012.

18. Wang F, Xia J, Wang N and Zong H: miR-145 inhibits proliferation and invasion of esophageal squamous cell carcinoma in part by targeting c-Myc. Onkologie 36: 754-758, 2013.

19. Cho WC, Chow AS and Au JS: MiR-145 inhibits cell proliferation of human lung adenocarcinoma by targeting EGFR and NUDT1. RNA Biol 8: 125-131, 2011.

20. Sachdeva M and Mo YY: MicroRNA-145 suppresses cell invasion and metastasis by directly targeting mucin 1 . Cancer Res 70: 378-387, 2010.

21. Cui SY, Wang R and Chen LB: MicroRNA-145: A potent tumour suppressor that regulates multiple cellular pathways. J Cell Mol Med 18: 1913-1926, 2014.

22. Lei C, Du F, Sun L, Li T, Li T, Min Y, Nie A, Wang X, Geng L, Lu Y, et al: miR-143 and miR-145 inhibit gastric cancer cell migration and metastasis by suppressing MYO6. Cell Death Dis 8: e3101, 2017.

23. Qiu T, Zhou X, Wang J, Du Y, Xu J, Huang Z, Zhu W, Shu Y and Liu P: miR-145, miR-133A and miR-133b inhibit proliferation, migration, invasion and cell cycle progression via targeting transcription factor Sp1 in gastric cancer. FEBS Lett 588: 1168-1177, 2014.

24. Gao P, Xing AY, Zhou GY, Zhang TG, Zhang JP, Gao C, Li H and Shi DB: The molecular mechanism of microRNA-145 to suppress invasion-metastasis cascade in gastric cancer. Oncogene 32: 491-501, 2013.

25. Livak KJ and Schmittgen TD: Analysis of relative gene expression data using real-time quantitative PCR and the 2(-Delta Delta C(T)) method. Methods 25: 402-408, 2001.

26. Guimarães RM and Muzi CD: Trend of mortality rates for gastric cancer in Brazil and regions in the period of 30 years (1980-2009). Arq Gastroenterol 49: 184-188, 2012.

27. Luo X, Burwinkel B, Tao S and Brenner H: MicroRNA signatures: Novel biomarker for colorectal cancer? Cancer Epidemiol Biomarkers Prev 20: 1272-1286, 2011.

28. Wang X, Tang S, Le SY, Lu R, Rader JS, Meyers C and Zheng ZM: Aberrant expression of oncogenic and tumor-suppressive microRNAs in cervical cancer is required for cancer cell growth. PLoS One 3: e2557, 2008. 
29. Iorio MV, Visone R, Di Leva G, Donati V, Petrocca F, Casalini P, Taccioli C, Volinia S, Liu CG, Alder H, et al: MicroRNA signatures in human ovarian cancer. Cancer Res 67: 8699-8707, 2007.

30. Liu X, Sempere LF, Galimberti F, Freemantle SJ, Black C, Dragnev KH, Ma Y, Fiering S, Memoli V, Li H, et al: Uncovering growth-suppressive MicroRNAs in lung cancer. Clin Cancer Res 15: 1177-1183, 2009.

31. Hermeking H and Eick D: Mediation of c-Myc-induced apoptosis by p53. Science 265: 2091-2093, 1994.

32. Maclean KH, Keller UB, Rodriguez-Galindo C, Nilsson JA and Cleveland JL: c-Myc augments gamma irradiation-induced apoptosis by suppressing Bcl-XL. Mol Cell Biol 23: 7256-7270, 2003.

33. Cannell IG, Kong YW, Johnston SJ, Chen ML, Collins HM, Dobbyn HC, Elia A, Kress TR, Dickens M, Clemens MJ, et al: p38 MAPK/MK2-mediated induction of miR-34c following DNA damage prevents Myc-dependent DNA replication. Proc Natl Acad Sci USA 107: 5375-5380, 2010.
34. Shao Y, Qu Y, Dang S, Yao B and Ji M: MiR-145 inhibits oral squamous cell carcinoma (OSCC) cell growth by targeting c-Myc and Cdk6. Cancer Cell Int 13: 51, 2013.

35. De Luca A, Maiello MR, D'Alessio A, Pergameno $M$ and Normanno N: The RAS/RAF/MEK/ERK and the PI3K/AKT signalling pathways: Role in cancer pathogenesis and implications for therapeutic approaches. Expert Opin Ther Targets 16 (Suppl 2): S17-S27, 2012.

36. Aksamitiene E, Kiyatkin A and Kholodenko BN: Cross-talk between mitogenic Ras/MAPK and survival PI3K/Akt pathways: A fine balance. Biochem Soc Trans 40: 139-146, 2012.

37. Kessenbrock K, Plaks V and Werb Z: Matrix metalloproteinases: Regulators of the tumor microenvironment. Cell 141: 52-67, 2010.

This work is licensed under a Creative Commons Attribution-NonCommercial-NoDerivatives 4.0 International (CC BY-NC-ND 4.0) License. 